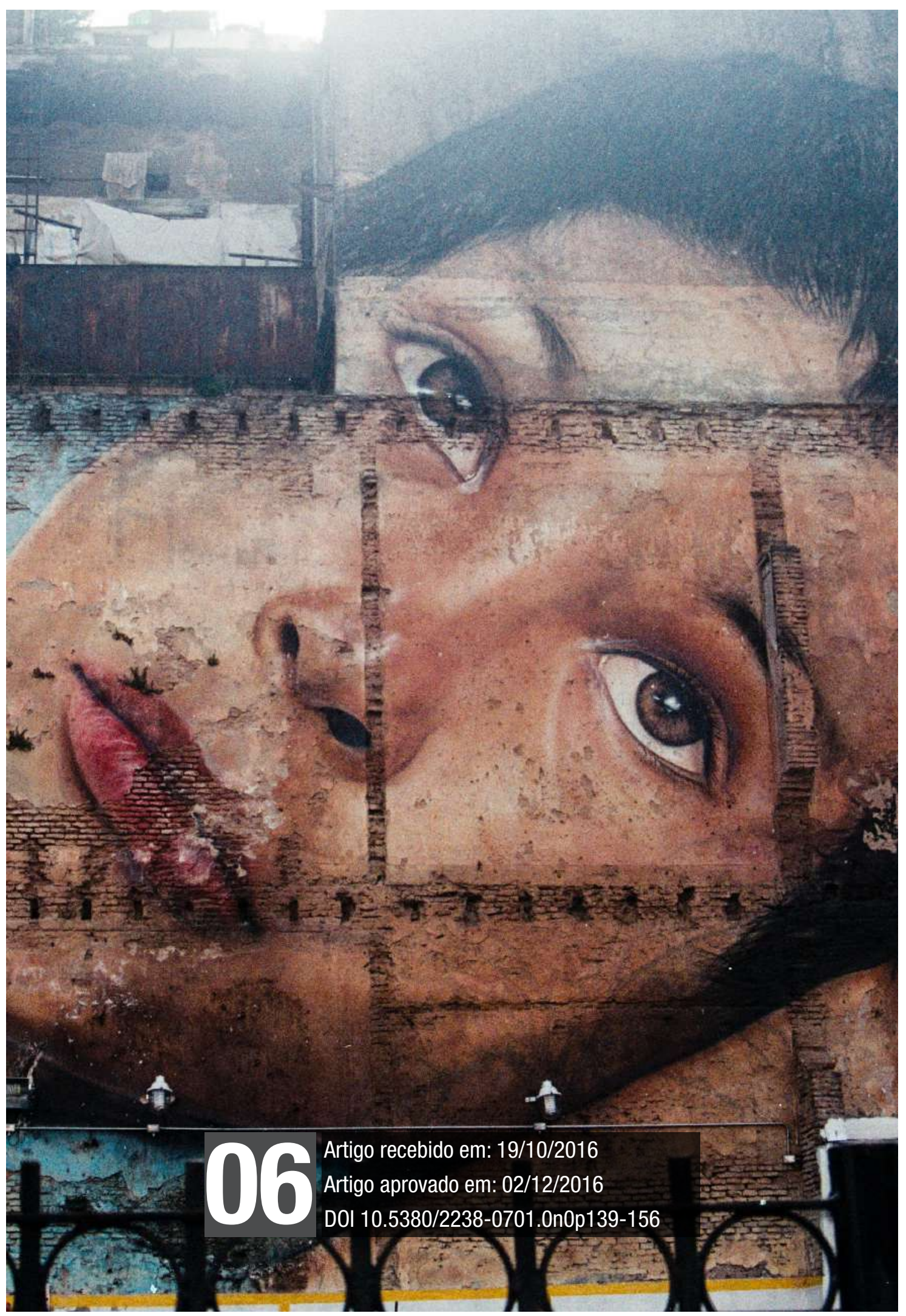


Diversidade Sexual. Sexualidade. Lesbianidade. Kit Anti-Homofobia. 


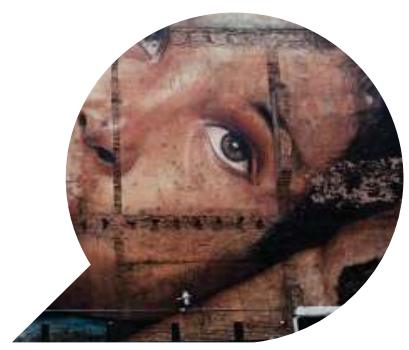

\title{
Kit Anti-Homofobia: o vídeo Torpedo e suas tramas sobre a lesbianidade
}

\author{
Anti-homophobia kit: the Torpedo video and his \\ plots about lesbianism
}

\author{
Kit Anti-Homofobia: el video Torpedo \\ $y$ sus parcelas en el lesbianismo
}

RICARDO DESIDÉRIO DA SILVA ${ }^{1}$

Resumo: Considerando a importância de reflexões que possibilitem debates frente a temática da diversidade sexual a partir de propostas eficazes e metodologias adequadas, como a utilização de vídeos como recurso pedagógico, este artigo tem por objetivo descrever e analisar criticamente o vídeo Torpedo que compõem o "DVD Torpedo", parte integrante do material do Kit Anti-Homofobia. A partir de uma descrição geral de seu conteúdo, forma e imagens, foram organizadas duas categorias de conteúdo temáticas: (1) Sexismo e heteronormatividade na escola e na família e (2) Olhares para subjetividade o que puderam evidenciar que o vídeo reafirma estereótipos e constroem as bases para o estabelecimento do que é considerado como aceitável, "normal", e do que

\footnotetext{
${ }^{1}$ Doutor em Educação Escolar, na linha de pesquisa em Sexualidade, Cultura e Educação Sexual pela UNESP/Araraquara-SP. Professor no Curso de Pedagogia da UNESPAR - Universidade Estadual do Paraná, Campus de Apucarana-PR e Professor do Programa de Pós-graduação em Educação Sexual, UNESP, Araraquara-SP. E-mail: contatodesiderio@hotmail.com.
} 
é diferente e que deve ser excluído, nos possibilitando assim, dialogar a partir de sua resignificação para a utilização como material educativo na escola.

Palavras-chave: Diversidade Sexual; Sexualidade; Lesbianidade; Kit Anti-Homofobia.

Abstract: Considering the importance of reflections that enable debates forward the issue of sexual diversity from effective proposals and appropriate methodologies such as the use of video as an educational resource, this article aims to describe and critically analyze the Torpedo video that make up the DVD "Torpedo" integral part of the material of the Anti-Homophobia Kit. From a general description of its content, form and pictures, they were organized two thematic content categories: (1) Sexism and heteronormativity in school and in the family and (2) looks for subjectivity which could show the video reaffirms stereotypes and build the foundation for the establishment of what is considered as acceptable, "normal" and what is different and should be deleted, allowing us thus dialogue from their reframing for use as educational material in school.

Keywords: Sexual Diversity; Sexuality; Lesbianism; Anti-homophobia kit.

Resumen: Teniendo en cuenta la importancia de las reflexiones que permiten discusiones reenviar el tema de la diversidad sexual por parte de las propuestas eficaces y metodologías apropiadas, tales como el uso del video como un recurso educativo, este artículo tiene como objetivo describir y analizar críticamente el video Torpedo que componen "DVD Torpedo", parte del material del Kit anti-Homofobia. Desde una visión general de su contenido, la forma y las imágenes, se organizaron dos categorías de contenido temático: (1) El sexismo y la heteronormatividad en la escuela y la familia y (2) se ve a la subjetividad que podría demostrar que el video reafirma los estereotipos y sentar las bases para el establecimiento de lo que se considera como aceptable, "normal" y lo que es diferente y debe suprimirse, permitiéndonos así el diálogo de su reformulación para su uso como material educativo en la escuela.

Palabras clave: Diversidad Sexual; La sexualidad; Lesbianismo; Kit Anti-homofobia. 


\section{Introdução}

Ao se pensar na temática da sexualidade em um trabalho de Educação Sexual na escola, nós, educadores, devemos perceber a importância quanto a inserção de alguns temas que deverão fazer parte das discussões e atividades planejadas, entre eles gênero e diversidade sexual. Afinal, vários são os desafios que ainda estão impregnados aos tabus e concepções puritanistas de uma sociedade fundada e substancialmente impregnada de proibições religiosas, em que há questões de preconceito ligadas diretamente à expressão da sexualidade. Além disso, infelizmente ainda há por parte da sociedade e aqui estão inseridos alguns professores que mantém o predomínio de uma visão heteronormativa, em que a única possibilidade de relacionamento amoroso e sexual legítima seria a que ocorre entre homens e mulheres. Na escola, segundo Rodrigues, Amaral, Giuzio e Maia (2011), o despreparo de professores também se dá pela falta de conhecimento sobre o assunto, além do preconceito e dificuldades em tratar o tema na escola.

Para Louro (2013), a noção de gênero e sexualidade ainda é muito simplista nas escolas, em seus currículos e práticas. Segundo a autora, "é consenso que a instituição escolar tem obrigação de nortear suas ações por um padrão: haveria apenas um modo adequado, legítimo, normal de masculinidade e de feminilidade e uma única forma sadia e normal de sexualidade, a heterossexualidade" (p. 45). Logo, pode-se pensar que a escola acredita, que ao se afastar desse padrão heteronormativo estaria se desviando, tornando assim, o que a autora chama de excêntrico - extravagante/esquisito, o que não é verdade.

Contudo, sabemos que o desejo sexual não se dá unicamente da forma como aprendemos. No caso do direcionamento do desejo ao objeto erótico, temos concebido, para fins de identidade, que a orientação sexual de uma pessoa, seja entre sexos opostos, mesmo sexo ou ambos, seja nomeada como heterossexualidade, homossexualidade e bissexualidade, respectivamente.

Meyer (2013) acredita que, na escola, devemos investir em projetos educativos que possibilitem mudar os processos de ensino-aprendizagem, onde o aluno não dependa de respostas prontas, mas que ele mesmo seja capaz de elaborar suas próprias perguntas. Logo, ao se pensar em ações que possibilitem diálogos sobre as questões de gênero na escola precisamos inicialmente refletir como tem sido e como está di- 
recionado o nosso olhar sobre estas questões: será que a escola reconhece as diferenças no modo em que são tratados os meninos e meninas? Estamos conseguindo valorizar a importância de uma educação mais igualitária? Temos identificado na prática pedagógica as segmentações/ diferenciações nas brincadeiras entre meninos e meninas? Os comportamentos de meninos e meninas são observados a fim de possibilitarmos mudanças para uma convivência mais harmoniosa, sem diferenças em seu tratamento?

Estas, entre tantas outras perguntas são necessárias, pois só assim poderemos refletir inicialmente sobre nossas reais ações no cotidiano escolar. A escola, ao afirmar que não há diferenciação no tratamento entre meninos e meninas, já assume muitas vezes o seu descompromisso frente às mudanças tão necessárias em todo processo de aprendizado e posturas frente às discriminações existentes em nossa sociedade. Porém, quando a escola assume seu compromisso numa educação igualitária, ela passa a fazer parte de um processo muito importante de aceitar uma mudança de postura, o que a permitirá buscar alternativas de mudanças para estes tratamentos inadequados, muitas vezes discriminatórios.

Diante do exposto, considera-se importante analisar materiais que, em tese, seriam destinados à problematização dessa temática no contexto escolar, como o vídeo descrito a seguir.

\section{Método}

Este trabalho caracteriza-se por uma pesquisa qualitativa descritiva, tipo documental que tem por objetivo descrever e analisar o objeto de análise do presente artigo que é o vídeo "Torpedo", parte integrante do kit anti-homofobia ${ }^{1}$, sendo o mesmo pertencente ao "DVD Torpedo" (nome dado ao conjunto dos três vídeos). Mesmo sendo vetado sua distribuição, o vídeo pode ser encontrado no site YouTube ${ }^{2}$.

O presente artigo discorre sobre a análise deste vídeo, tanto em seu conteúdo (transcrito) quanto em suas imagens, a partir da técnica da Análise de Conteúdo, segundo a modalidade denominada Temática, conforme o que dispõe Bardin (2007).

\footnotetext{
${ }^{1}$ O Kit anti-homofobia é composto pelo Caderno Escola Sem Homofobia; Boleshs (Boletins Escola sem Homofobia); cartilhas, cartazes, carta de apresentação e os audiovisuais. Esse material foi elaborado exclusivamente para o trabalho com alunos do Ensino Médio.

2 “Torpedo". Disponível em: <http://www.youtube.com/watch?v=TP_0jE_Fi2o\&feature=related>.
} 


\section{Resultados e discussão: Descrição do material ${ }^{3}$}

O DVD Torpedo faz parte do kit de material do Projeto Escola sem Homofobia, que tem por objetivo a promoção do reconhecimento da diversidade de orientação sexual e de identidade de gênero e do enfrentamento à homofobia, à lesbofobia e à transfobia nas escolas.

Três vídeos/histórias (Torpedo, Encontrando Bianca e Probabilidade) compõem o DVD Torpedo, porém para este artigo tomaremos como base apenas o vídeo Torpedo (mesmo nome do conjunto dos três vídeos). Com duração de 3'58”, o vídeo traz uma sequência de 116 planos e nele, percebemos pontos relevantes a serem observados em sua narrativa. Com base nas unidades temáticas foi possível compreender, interpretar e analisar suas tramas. Assim, destacam-se duas categorias temáticas e suas intencionalidades presentes no vídeo Torpedo:

\section{TEMA 01: Sexismo e heteronormatividade na escola e na família}

No vídeo Torpedo, logo que Ana Paula envia o torpedo, Vanessa o recebe e é possível observar detalhadamente as relações de gênero na educação física escolar, em que ela (Vanessa) estava participando de uma aula de educação física onde não há a presença de meninos, só de meninas. Este tipo de abordagem ainda é frequente nas aulas de educação física, conforme nos apresentam Abreu (1995), Altmann (1998), Souza e Altmann (1999) e Dornelles (2007 e 2011).

Altmann (1998) afirma que há uma grande evidência de que o esporte é uma atividade predominantemente masculina e o que poderia proporcionar aos alunos a superação das relações desiguais de gênero, acaba não acontecendo nestas aulas por meio de seus educadores. Para a autora, separar meninos e meninas nas aulas é "tornar as fronteiras das divisões de gênero mais rígidas do que de fato são e negar a meninas e meninos a possibilidade de cruzá-las; é furtar-lhes de antemão a possibilidade de escolha entre estarem juntos e separados" (ALTMANN, 1998, p. 103)

No vídeo, as alunas estão apenas tocando a bola alternadamente uma para outra. Com isso, a ação expressa no vídeo é reforçar que elas são/estão excluídas de outras atividades por serem fracas, meigas e delicadas. Isto acaba corroborando exatamente com o que nos afirma

\footnotetext{
${ }^{3}$ Estas informações fazem parte do "Guia de discussão e proposta de dinâmicas para trabalhar com o DVD”. Torpedo/Escola Sem Homofobia. s/n.
} 
Gonçalves:

[...] Nas atitudes sexistas comuns em escolas, por exemplo, estão aquelas que ricularizam expressões de emoção nos garotos ou de rebeldia nas garotas. Ambos estão fora dos padrões estabelecidos nos quais prevalece a tese de que rebeldia e agressividade são atributos masculinos, e afetividade e emotividade, femininos (GONÇALVES, 1999, p. 203).

Por se tratar de um vídeo educativo, estes fragmentos do material não deveria reforçar esta segmentação de meninos e meninas nas aulas de educação física. Para Dornelles (2011) esta forma de ser menino e de ser menina "produz hierarquias e desigualdades" (p. 27).

No vídeo Torpedo pode haver uma afirmação quanto aos estereótipos e/ou reforçando a heteronormatividade, além é claro da violência (bullying ${ }^{4}$ ) sofrida por elas (Vanessa e Ana Paula) na exposição das imagens sem autorização. Entretanto, duas são as possibilidades de análise quanto às fotos apresentadas no vídeo. As imagens (fotos) revelam a orientação sexual de Ana Paula e Vanessa - fato muito afirmativo no material. Porém duas são as possibilidades de recepção: a primeira é de um material educativo afirmar ou querer nos transmitir uma verdade a partir de estereótipos (imagens expressas na foto) quanto à orientação sexual.

Todo diálogo na história se dá por conta de uma conversa entre Ana Paula e Vanessa pelo celular sobre as fotos que foram divulgadas na escola. Quando Ana Paula digita "Me ligue urgente!" para Vanessa nos dá uma ideia de algo preocupante, uma atenção especial que se deve dar com a mensagem recebida. Esta ação é um fato confirmado quando Vanessa logo após receber o torpedo, liga para Ana Paula:

Vanessa: Oi Aninha! Onde você tá?

Ana Paula: Van aconteceu uma coisa horrível! Alguém tirou umas fotos da gente na festa e colocou na internet!

Vanessa: Não acredito!

Ana Paula: E ainda por cima coloram uma foto na parede do corredor. Tá todo mundo vendo. Tô morrendo de vergonha! Vem correndo pro banheiro!!

\footnotetext{
${ }_{4}$ Bullying é um termo da língua inglesa (bully = "valentão"), que se refere para todas as formas de agressão, verbal ou física, repetitivas e intencionais. Os casos de bullying têm o objetivo de intimidar ou agredir a outra pessoa, sem ter a possibilidade de defesa. 0 bullying é um problema de caráter mundial, que atinge crianças de todas as idades e posição social. Além da agressão é considerado bullying apelidos que humilham as crianças. Disponível em < http://amadurecenciaa. wordpress.com/page/2/>. Acesso em 21 jul. 2014.
}

5 Transcrição do autor. 
Se fizéssemos o mesmo exercício apresentado por Pamplona (2012) em sua Dissertação, de assistirmos ao vídeo Torpedo sem áudio. As imagens por si só não revelam a atração afetivo-sexual de Ana Paula e Vanessa. Entretanto, toda atenção se dá a estas imagens e aos diálogos trocados entre elas no vídeo, que afirmam assumir sua lesbianidade. $\mathrm{Ou}$ seja, só porque elas estão juntas nas fotos, isto justificaria a orientação sexual delas.

Mott (2003, p. 15-16), ao apresentar os tipos de homossexuais, faz um lembrete muito importante:

[...] a aparência externa não traduz necessariamente as fantasias e práticas sexuais individuais, pois há efeminados que não são gays, e machões que na cama viram "fobonecas". Há muitos estilos de vida, várias formas de viver suas preferências sexuais. Todos têm direito de viver como querem, desde que respeitem a liberdade alheia. Temos que aprender a conviver com a diversidade, aceitar o pluralismo, respeitar o diferente. Cada qual se assume quando e o quanto quiser. Em questão de sexualidade não há receita única, nada é completamente certo ou errado. $\mathrm{O}$ único limite à nossa liberdade sexual é a liberdade alheia. Cada qual na sua e todo mundo numa boa.

Embora Mott (2003) faça referência aos gays, tais observações são importantes para quaisquer pessoas. Não podemos julgá-las por sua aparência ou estereótipos, como foi dada tanta importância às fotografias no vídeo.

Por outro lado, uma segunda percepção nos é dada se observarmos a existência na intersecção entre heterossexualidade e gênero (LOURO, 2009). Para a autora, "temos de reconhecer que sexualidade e gênero estão profundamente articulados, talvez mesmo, muito frequentemente, se mostrem confundidos" (2009, p. 91). Louro (2009) ao afirmar esta intersecção, nos diz que as questões de gênero acabam tendo mais efeito. Lembrando-nos do quanto é comum "atribuir a um homem homossexual a qualificação de 'mulherzinha' ou supor que uma mulher lésbica seja uma mulher-macho" (p. 91).

Para Louro (2009), em nossa cultura, a heteronormatividade se dá de forma muito mais intensa e/ou mais visível em relação ao gênero masculino.

Observamos que desde os primeiros anos de infância os meninos são alvo de uma especialíssima atenção na construção de uma sexualidade heterossexual. As práticas afetivas entre meninas e mulheres 
costumam ter, entre nós, um leque de expressões mais amplo do que aquele admitido para garotos e homens. A intimidade cultivada nas relações de amizade entre mulheres e a expressão da afetividade por proximidade e toques físicos são capazes de borrar possíveis divisórias entre relações de amizade e relações amorosas e sexuais. Daí que a homossexualidade feminina pode se construir de forma mais invisível. Abraços, beijos, mãos dadas, a atitude de 'abrir o coração' para a amiga/parceira são práticas comuns do gênero feminino em nossa cultura. Essas mesmas práticas não são, contudo, estimuladas entre os meninos ou entre os homens. A 'camaradagem' masculina tem outras formas de manifestação: poucas vezes é marcada pela troca de confidências e o contato físico, ainda que seja plenamente praticado em algumas situações (nos esportes, por exemplo), se dá cercado de maiores restrições entre eles do que entre elas (não só quanto às áreas do corpo que podem ser tocadas como do tipo de toque que é visto como adequado) (LOURO, 2009, p. 91).

As mãos dadas, o abraço e até mesmo as trocas de olhares apresentadas por Ana Paula e Vanessa no vídeo são o que Louro (2009) afirma ser práticas comuns do gênero feminino em nossa sociedade. Isto, de certa forma, não justifica tamanha importância que se deu as imagens das fotografias apresentadas no vídeo, pois não é por estarem próximas em uma fotografia que se pode afirmar que as duas são lésbicas, como o fez. O fato é que tal destaque a essas imagens reforçam os estereótipos das meninas e são utilizadas exclusivamente para determinar a orientação sexual delas (justificativa dada também para que elas se assumissem na escola) e não de nos alertar quanto ao poder heteronormativo ainda presente em nossa sociedade, principalmente em relação a maior invisibilidade da homossexualidade feminina.

Quanto à lesbofobia - que é a "soma de discriminações que se manifestam conjuntamente: a discriminação por ser mulher e a discriminação por orientação sexual" (CAVALEIRO, 2014), podemos observar no vídeo Torpedo que não há um trabalho de conscientização a este tipo de preconceito.

Louro (2007) nos afirma que "consentida e ensinada na escola, a homofobia expressa-se pelo desprezo, pelo afastamento, pela imposição do ridículo" (p. 29). Este desprezo e a imposição do ridículo são muito evidentes nos rostos dos alunos ao visualizarem as imagens, assim como quando Ana Paula está caminhando pelo corredor.

Neste sentido, Ana Paula e Vanessa passam por uma situação, evolvendo o desprezo e a ridicularização, bastante comum e infelizmente 
muito evidente nas escolas. Elas, além de assumirem este grupo minoritário, a reação dos alunos - claramente exposto no vídeo - é como se a homossexualidade fosse contagiosa, "cria-se uma grande resistência em demonstrar simpatia para com sujeitos homossexuais: a aproximação pode ser interpretada como uma adesão a tal prática ou identidade" (LOURO, 2007, p. 29).

Cavaleiro (2009), em sua Tese "Feminilidades homossexuais no ambiente escolar: ocultamentos e discriminações vividas por garotas" procurou compreender o papel das relações de gênero e da sexualidade "na edificação concreta e simbólica do cotidiano da escola para indagar [...] como as feminilidades homossexuais são vividas, produzidas, mantidas e reproduzidas por garotas, entre 16 e 17 anos, que se consideram lésbicas, homossexuais ou bissexuais" (p. 9) em uma escola pública de ensino médio na cidade de São Paulo.

Com base em sua Tese, pode-se observar que a autora examinou os modos pelos quais as garotas "elaboram suas experiências, como vivenciam as interações, a sociabilidade e como constroem suas identidades no ambiente escolar" (p. 18). Se atrelarmos ao vídeo Torpedo, percebese que Ana Paula e Vanessa vivenciam suas experiências sob a ordem do que Cavaleiro (2009) denomina de discriminação indireta e antecipada.

Conferindo o sentido de alienada, distinta, separada, ou seja, apartada socialmente dos demais, a experiência e vivência da sexualidade na vida dessas garotas, na escola, é colocada sob a ordem da discriminação indireta, nem por isso, menos grave, e da discriminação antecipada (ou temida), que em conformidade com uma ordem hipócrita, confina a homossexualidade no âmbito privado e impede sua expressão pública na relação de afeto e amor. Ainda que por meio de uma discriminação indireta - que por ser indireta não é menos grave - as garotas são impedidas de manifestarem publicamente seus afetos, numa ordem que ensina que é necessário não 'molestar' os 'outros' nas interações sociais no ambiente escolar (CAVALEIRO, 2009, p. 144-145)

Esta discriminação, mesmo que indireta é, sem dúvidas, um traço muito evidente da lesbofobia e de tantas outras desigualdades na escola. Entretanto, um material que parte da iniciativa da garantia dos direitos humanos, orientação sexual e identidade sexual e gênero no âmbito escolar se esquiva de seus objetivos, principalmente em ausentar as figuras mais importantes da escola: gestores e pais.

No vídeo torpedo a única figura adulta que é apresentada é uma au- 
xiliar de limpeza que transmite um olhar de desaprovação a Ana Paula e Vanessa, devido às fotografias, que provavelmente ela também tenha visto. Não desmerecendo a importância e valor que sua figura é na escola, a auxiliar de limpeza (do vídeo) não representa a direção, equipe pedagógica, professores e pais. Desta forma, não há como alcançar quaisquer objetivos se estes profissionais não estiverem envolvidos, principalmente se tratando de um trabalho de Educação Sexual na escola.

Há então, um silenciamento da escola sobre a discriminação, exclusão e até sob o controle da homossexualidade (CAVALEIRO, 2009).

O processo de invisibilização de homossexuais, bissexuais e transgêneros no espaço escolar precisa ser desestabilizado. [...], as temática relativas às homossexualidades, bissexualidades e transgeneridades são invisíveis no currículo, no livro didático e até mesmo nas discussões sobre direitos humanos na escola (JUNQUEIRA, 2009, p. 31)

Com isso, o vídeo deixa clara a função da escola. E é exatamente o que Junqueira (2009) nos afirma quando diz que "a escola configura-se um lugar de opressão, discriminação e preconceitos, no qual e em torno do qual existe um preocupante quadro de violência a que estão submetidos milhos de jovens e adultos LGBT" (p. 15). Para o autor, toda essa violência se faz "com a participação ou a omissão da família, da comunidade escolar, da sociedade e do Estado" (idem), tornando-se assim, conforme nos apresenta Peres (2009), “[...] escola-política, escola-igreja, escola-tribunal, orientadas por tecnologias sofisticadas de poder centradas na disciplina dos corpos e na regulação dos prazeres" (p. 249).

Como afirma Louro (1997, p. 67-68), "ao não falar a respeito deles e delas, talvez se pretenda 'eliminá-los', ou, pelo menos, se pretenda evitar que os alunos e as alunas 'normais' os/as conheçam e possam desejá-los/ as. Aqui, o silenciamento - ausência da fala - aparece como uma espécie de garantia da norma”. Talvez este silenciamento (representado pela auxiliar de limpeza no vídeo Torpedo), seja uma espécie de garantia da norma aplicado ao material.

Em outro ponto observável no vídeo Torpedo, devemos nos perguntar se o material estaria nos proporcionando uma educação ou deseducação sexual? Este fato se dá, pois é evidente que os sorrisos expressos pelos dois garotos nos chamam atenção quando Ana Paula e Vanessa se abraçam. O vídeo Torpedo consegue num primeiro momento fazer algo muito positivo nessas expressões, - o resgate do erótico. Resgatar 
o erótico é "encarar a sexualidade como algo bonito e bom na vida das pessoas, lutando por eliminar a visão que tem predominado: a de algo 'sujo,' 'feio' e 'vergonhoso', assim como a visão de que é um assunto do qual não se deve falar” (FIGUEIRÓ, 2010, p. 131).

E é exatamente o regaste erótico, que possibilitaria a todos perceber/sentir/compreender a passagem de uma sexualidade "vulgar" (todos os olhares de desprezo dos outros alunos) para uma sexualidade compreendida e vivida de forma positiva por meio de sua beleza, sem preconceitos e tabus (o abraço entre Vanessa e Ana Paula). Entretanto, esse "resgate de gênero" denominado pela autora passa a não existir se tivermos um olhar malicioso, conforme apresentou Pamplona (2012), analisando os mesmos planos das imagens do vídeo Torpedo em sua Dissertação:

Esses recursos utilizados, das faces sorridentes e olhares entusiasmados, não estão postos nas imagens ao acaso, antes parecem pretender trazer em pauta outra discussão referente à realidade frequentemente vista nas práticas de discriminações enfrentadas por mulheres lésbicas. Nesse exemplo os olhares maliciosos dos garotos extasiados com a cena do abraço entre duas mulheres retratam um padrão conhecido na cultura androcêntrica e machista, que só admite o contato íntimo e sexual entre duas mulheres quando essas são tomadas como objetos da satisfação sexual masculina. O que é abundantemente visto em filmes pornográficos, os quais frequentemente exibem atos de cenas sexuais entre um homem e duas mulheres, que trocam carícias entre si. Esse tipo de aceitação, ou melhor, de consentimento da relação lésbica, ocorre de maneira transitória e pontual, somente quando essas são objetificadas e disponibilizadas para o contentamento libidinal masculino (PAMPLONA, 2012, p. 74)

Entretanto, este olhar malicioso identificado por Pamplona (2012) no vídeo Torpedo, nos leva a pensar que a Educação Sexual, segundo Vasconcelos (1971) "se fundamenta também no fato de que essa educação, em sua tarefa crítica, não pode deixar de considerar que a sexualidade 'chega' ao indivíduo já ligada a uma estética negativa” (p. 110).

Nosso papel então é denunciar esta visão (imposta no vídeo Torpedo) à sexualidade, e o condicionamento cultural que daí se segue, como o verdadeiro incentivo à pornografia. Pornografia esta "apresentada numa perspectiva moralista, como uma inclinação para a devassidão" (VASCONCELOS, 1971, p.111). 


\section{TEMA 02: Olhares para subjetividade}

O vídeo Torpedo nos chama a atenção nos planos iniciais de Ana Paula digitando a mensagem (torpedo) a Vanessa, que deixam claro sua preocupação quanto à exposição (à suposta evidência) de sua orientação sexual - expor sua intimidade. Fruto de um impedimento (uma norma) da própria escola.

Expressar os sentimentos não necessariamente é uma ação comum observada nas escolas, pois educadores afirmam se tratar de uma particularidade de cada ser humano (DINIS, 2011). Britzman (1996) considera tal atitude um mito ao afirmar ser duvidosa esta noção de privacidade. Para a autora,

[...] a insistência de que a sexualidade deva ser confinada à esfera privada reduz a sexualidade às nossas específicas práticas sexuais e individuais, impedindo que concebamos a sexualidade como sendo definida no espaço social mais amplo, através de categorias e fronteiras sociais (1996, p. 80)

Como a intenção do material é revelar a lesbianidade de Ana Paula e Vanessa (fato que ainda é questionável) podemos afirmar que fica evidente o quanto a escola ainda colabora para negação e ignorância da homossexualidade, possibilitando ser

[...] um dos espaços mais difíceis para que alguém "assuma" sua condição de homossexual ou bissexual. Com a suposição de que só pode haver um tipo de desejo e que esse tipo - inato a todos - deve ter como alvo um indivíduo do sexo oposto, a escola nega e ignora a homossexualidade (provavelmente nega porque ignora) e, desta forma, oferece muito poucas oportunidades para que adolescentes ou adultos assumam, sem culpa ou vergonha, seus desejos. O lugar do conhecimento mantém-se, com relação à sexualidade, como lugar do desconhecimento e da ignorância (LOURO, 2007, p. 30)

E esta ignorância, tão evidente na escola, fica ainda mais clara se pensarmos "[...] como os discursos dominantes da heterossexualidade produzem seu próprio conjunto de ignorâncias tanto sobre a homossexualidade quanto sobre a heterossexualidade" (BRITZMAN, 1996, p. 92).

No vídeo, não há qualquer indício de que realmente se confirma ser uma festa. E se realmente esta festa existiu, as mesmas estavam fora 
dela - excluídas. Uma vez que estas imagens, como apresentado no vídeo revelam a orientação sexual das duas e por sua simplicidade de não afirmar nada, não poderiam ter sido tiradas dentro da própria festa?

Neste sentido, o vídeo poderia propor a inserção das estudantes lésbicas na festa, sem ter que excluí-las. Entretanto, a exclusão da festa, "pode ser ainda mais forte em relação às jovens e faz com que as estudantes lésbicas (e não apenas elas) se tornem ainda mais invisíveis" (JUNQUEIRA, 2009, p. 31). Porém, acredito que este não tenha sido um dos objetivos do material, apenas uma desatenção quanto à sua produção.

\section{Considerações finais}

Ao se pensar no vídeo enquanto ferramenta pedagógica, antes mesmo de uma análise do material, é preciso refletir sobre o papel do vídeo não mais como um material singular e pouco instigante às pesquisas e análises mais atentas, considerado muitas vezes apenas como entretenimento em seu uso pelos professores, como nos afirmou Almeida (2004).

A análise crítica do vídeo desvelou duas categorias temáticas: Sexismo e heteronormatividade na escola e na família e Olhares para subjetividade. Nas discussões sobre sexismo e heteronormatividade na escola e na família, inseridas nas análises deste trabalho (TEMA 01), o vídeo reafirma estereótipos e constroem as bases para o estabelecimento do que é considerado como aceitável, "normal", e do que é diferente, a ser excluído.

Uma das primeiras constatações observadas no vídeo foi verificar a segmentação de meninas e meninos nas atividades físicas da escola, especificamente como é mostrado no vídeo Torpedo. Quanto aos estereótipos, o material traz evidentemente muitos elementos que nos remete a uma preocupação quanto à violência sofrida (bullying) por algumas das personagens.

Observa-se a partir dessas análises que há uma ausência tanto na interlocução entre a lesbofobia sofrida pelos personagens e a figura de um adulto na intervenção de tais ações. Confirmando assim um silenciamento, descompromisso e exclusão da escola, o que evidenciaria tamanha violência sofrida por tantas pessoas, principalmente no âmbito escolar.

$\mathrm{O}$ material consegue, num primeiro momento, fazer algo muito positivo quanto à dimensão estética da sexualidade, onde é possível perceber/sentir/compreender a passagem de uma sexualidade "vulgar" (todos os olhares de desprezo dos outros alunos) para uma sexualidade 
compreendida e vivida de forma positiva por meio de sua beleza, sem preconceitos e tabus (o abraço entre Vanessa e Ana Paula). Entretanto, essa percepção deixa de existir se tivermos um olhar malicioso dos personagens, não percebendo mais a sexualidade como algo positivo, mas sim por não se passar de uma estética negativa, ligada à pornografia.

A dificuldade em assumir-se surge, portanto, nas discussões da segunda categoria, cujo olhar se dá para subjetividade das personagens (TEMA 02). Durante a trajetória da análise pertinente a essa temática, observa-se que as personagens que vivem num ambiente escolar predominantemente heterossexual temem pela descoberta da sua identidade de gênero. Fruto de um impedimento (uma norma) da própria escola. $\mathrm{O}$ material apresenta o preconceito evidente nas escolas, e não ousa avançar em nenhuma das esferas nas discussões desse conflito.

Fica evidente a própria repressão sexual exercida pela escola (instância de controle social), traduzindo-se em um estabelecimento de padrões e comportamentos fixos e imutáveis. O vídeo sem dúvida perde oportunidade de questionamentos quanto às representações que dão sentido ao material, reforçando as relações de poder existentes em nossa sociedade.

\section{REFERÊNCIAS}

ABREU, Neíse Gaudêncio. Análise das percepções de docentes e discentes sobre turmas mistas e separadas por sexo nas aulas de educação física escolar. In: ROMERO, Eliane (org.), Corpo, mulher e sociedade. Campinas: Papirus, 1995, p. 157-176.

ALMEIDA, Milton José. Imagens e sons: a nova cultura oral. 3 ed., S.P.: Cortez, 2004.

ALTMANN, Helena. Rompendo fronteiras de gênero: Marias [e] homens na educação física. 1998. Dissertação (Mestrado em Educação) - Faculdade de educação, Universidade Federal de Minas Gerais, Belo Horizonte, 1998.

BARDIN, Laurence. Análise de Conteúdo. Trad. Luis Antero Reto e Augusto Pinheiro Lisboa. Lisboa: Edições 70, 2007.

BOURDIEU, Pierre. Questões de sociologia. Rio de Janeiro: Marco Zero, 1983.

BRITZMAN, Deborah. O que é essa coisa chamada amor: identidade homossexual, educação e currículo. Educação e Realidade, Porto Alegre, v. 21, n. 1, jan./jul. 1996. 
CAVALEIRO, Maria Cristina. Feminilidades homossexuais no ambiente escolar: ocultamentos e discriminações vividas por garotas. 2009, 217f. Tese (Doutorado em Educação) - Faculdade de Educação, Universidade de São Paulo. São Paulo: 2009.

A sexualidade é política: heterossexualidade compulsória e lesbofobia nas escolas. In: MAIA, Jorge Sobral da Silva; BIANCON, Mateus Luiz. Educação das relações de gênero e em sexualidades: reflexões contemporâneas. $1^{\text {a }}$ ed. Curitiba: Appris, 2014.

DINIS, Nilson Fernando. Homofobia e educação: quando a omissão também é signo de violência. Educar em Revista. Curitiba, n.39, p. 39-50, jan./abr., 2011.

DORNELLES, Pricila Gomes. Distintos destinos? A separação entre meninos e meninas na Educação Física escolar na perspectiva de gênero. 2007, 156f. Dissertação (Mestrado em Educação) - Universidade Federal do Rio Grande do Sul. Faculdade de Educação, Porto Alegre, 2007.

. Marcas de gênero na Educação Física escolar: a separação de meninos e meninas em foco. Revista Motrivivência, n. 37, p. 12-29. Dez, 2011.

ECOS. Comunicação em Sexualidade. Projeto Escola sem Homofobia: Kit de material educativo Escola sem Homofobia. Disponível em <http://www.ecos.org.br/ projetos/esh/esh_kit.asp>. Acesso em: 06 de julho de 2014.

FIGUEIRÓ, Mary Neide Damico. (Org.). Homossexualidade e Educação Sexual: construindo o respeito à diversidade. Londrina: Eduel, 2007.

Educação Sexual: retomando uma proposta, um desafio. $3^{\text {a }}$.ed. rev. e atual. Londrina: Eduel, 2010.

JUNQUEIRA, Rogério. Homofobia nas Escolas: um problema de todos. In: JUNQUEIRA, R. (org). Diversidade Sexual na Educação: problematizações sobre a homofobia nas escolas. Brasília: Ministério da Educação, Secretaria de Educação Continuada, Alfabetização e Diversidade, UNESCO, 2009.

LOURO, Guacira Lopes. Pedagogias da Sexualidade. In: LOURO, Guacira Lopes (Org.); O Corpo Educado: pedagogias da sexualidade. Tradução

dos artigos: Tomaz Tadeu da Silva. 2 ${ }^{\text {a }}$ ed., $3^{\text {a }}$ reimpressão. Belo Horizonte: Autêntica, 2007. Heteronormatividade e Homofobia. In: JUNQUEIRA, Rogério. (org). Diversidade Sexual na Educação: problematizações sobre a homofobia nas escolas. Brasília: Ministério da Educação, Secretaria de Educação Continuada, Alfabetização e Diversidade, UNESCO, 2009. 
Currículo, gênero e Sexualidade: o "normal", o "diferente" e o "excêntrico". In: LOURO, Guacira Lopes; FELIPE, Jane; GOELLNER, Silvana Vilodre. Corpo, gênero e sexualidade: um debate contemporâneo na educação. 9 ed. Petrópolis, RJ: Vozes, 2013.

MELLO, Luiz; FREITAS, Fátima; PEDROSA, Claudio; BRITO, Walderes. Para além de um kit anti-homofobia: políticas públicas de educação para a população LGBT no Brasil. Revista Bagoas, n. 07, p. 99-122, 2012.

MEYER, Dagmar Estermann. Gênero e educação: teoria e política. In: LOURO, Guacira Lopes; FELIPE, Jane; GOELLNER, Silvana Vilodre. Corpo, gênero e sexualidade: um debate contemporâneo na educação. 9 ed. Petrópolis, RJ: Vozes, 2013.

MOTT, Luiz. Homossexualidade: mitos e verdades. Salvador: GGB, 2003.

PAMPLONA, Renata Silva. O kit anti-homofobia e os discursos sobre diversidade sexual. 2012, 147f. Dissertação (Mestrado em Educação) - Universidade Federal de São Carlos, São Carlos, 2012.

PERES, Wiliam Siqueira. Cenas de Exclusões Anunciadas: travestis, transexuais, transgêneros e a escola brasileira. In: JUNQUEIRA, Rogério. (org). Diversidade Sexual na Educação: problematizações sobre a homofobia nas escolas. Brasília: Ministério da Educação, Secretaria de Educação Continuada, Alfabetização e Diversidade, UNESCO, 2009.

RODRIGUES, Silvava T. K., AMARAL, Carolina B. de A., GIUZIO, Mariana F. \& MAIA, Ana Cláudia Bortolozzi. O despreparo de professores diante da educação sexual e diversidade sexual na escola. Psicopedagogia online: Educação \& Saúde, 2011. Disponível em: http://www.psicopedagogia.com.br/artigos/artigo. asp? entrID=1351. Acesso em: 30 set. 2012.

SILVA, Ricardo Desidério. Educação Audiovisual da Sexualidade: olhares a partir do Kit Anti-Homofobia. 2015, 144 f. Tese (Doutorado em Educação Escolar). Faculdade de Ciências e Letras, Universidade Estadual Paulista, Araraquara-SP, 2015.

SOUSA, Eustáquia Salvadora de, ALTMANN, Helena. Meninos e meninas: expectativas corporais e implicações na educação física escolar. Cadernos Cedes: corpo e educação, n. 48, p. 52-68, ago, 1999.

TORPEDO. $2^{\circ}$ de 3 Filmes Oficiais do Kit Gay do MEC: “Torpedo”. Disponível em: $<$ http://www.youtube.com/watch?v=TP_OjE_Fi2o\&feature=related $>$ Acesso em 07 de agosto de 2011.

VASCONCELOS, Naumi. Os dogmatismos sexuais. Rio de Janeiro: Paz e Terra, 1971. 